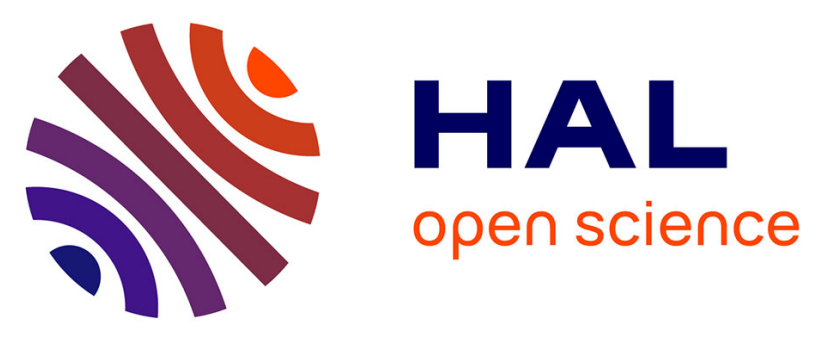

\title{
Light-Tissue Interaction Model for the Analysis of Skin Ulcer Multi-spectral Images
}

July Galeano, Pedro José Tapia-Escalante,, Sandra Milena Perez-Buitrago,, Yesid Hernandez-Hoyo, Luisa Fernanda Arias-Munoz, Artur Zarzycki, Johnson Garzon-Reyes, Franck Marzani

\section{To cite this version:}

July Galeano, Pedro José Tapia-Escalante,, Sandra Milena Perez-Buitrago,, Yesid Hernandez-Hoyo, Luisa Fernanda Arias-Munoz, et al.. Light-Tissue Interaction Model for the Analysis of Skin Ulcer Multi-spectral Images. 6th ECCOMAS Thematic Conference on Computational Vision and Medical Image Processing (VipIMAGE), ECCOMAS, Oct 2017, Porto, Portugal. pp.754-761, 10.1007/978-3319-68195-5_81. hal-01861360

\section{HAL Id: hal-01861360 https://u-bourgogne.hal.science/hal-01861360}

Submitted on 6 Jul 2021

HAL is a multi-disciplinary open access archive for the deposit and dissemination of scientific research documents, whether they are published or not. The documents may come from teaching and research institutions in France or abroad, or from public or private research centers.
L'archive ouverte pluridisciplinaire HAL, est destinée au dépôt et à la diffusion de documents scientifiques de niveau recherche, publiés ou non, émanant des établissements d'enseignement et de recherche français ou étrangers, des laboratoires publics ou privés. 


\title{
Light-Tissue Interaction Model for the Analysis of Skin Ulcer Multi-spectral Images
}

\author{
July Galeano ${ }^{1(凶)}$, Pedro Jose Tapia-Escalante ${ }^{2}$, \\ Sandra Milena Pérez-Buitrago ${ }^{3}$, Yesid Hernández-Hoyos ${ }^{4}$, \\ Luisa Fernánda Arias-Muñoz ${ }^{5}$, Artur Zarzycki ${ }^{6}$, Johnson Garzón-Reyes ${ }^{7}$, \\ and Franck Marzani ${ }^{8}$ \\ 1 Grupo de Investigación Materiales Avanzados y Energía -MatyEr-. Línea \\ Biomateriales y Electromedicina, Instituto Tecnológico Metropolitano - ITM, \\ Calle 54A No. 30-01, Medellín, Colombia \\ julygaleano@itm.edu.co
}

${ }^{2}$ Grupo de investigación en bioingeniería, Universidad Pontificia Bolivariana - UPB,

Circular 1a. 70-01, Medellín, Colombia ppeter_pp@hotmail.com

3 Grupo de Investigación e Innovación Biomédica -ITM- and Grupo de Dinámica

Cardiovascular - UPB, Instituto Tecnológico Metropolitano - ITM, Calle 73 No. 76A-354. UPB., Medellín, Colombia sandraperez@itm.edu.co

4 Ingeniería de Sistemas, Instituto Tecnológico Metropolitano - ITM, Medellín, Colombia yesidhernandezhoyos@gmail.com

${ }^{5}$ Ingeniería de Sistemas, Instituto Tecnológico Metropolitano - ITM, Medellín, Colombia luisa0118@gmail.com

${ }^{6}$ Grupo de Investigación Automática y Electrónica. Línea Sistemas de Control y Robótica, Instituto Tecnológico Metropolitano - ITM, Medellín, Colombia arturzarzycki@itm.edu.co

7 Grupo de Investigación de Óptica y Espectroscopía, Universidad Pontificia Bolivariana - UPB, Medellín, Colombia johnson.garzon@upb.edu.co

8 Laboratoire Le2i, UFR Sciences et Techniques, Université de Bourgogne, B.P. 47870, 21078 Dijon Cedex, France franck.marzani@u-bourgogne.fr

\begin{abstract}
Skin ulcers (SU) are ones of the most frequent causes of consultation in primary health-care units (PHU) in tropical areas. However, the lack of specialized physicians in those areas, leads to improper diagnosis and management of the patients. There is then a need to develop tools that allow guiding the physicians toward a more accurate diagnosis. Multi-spectral imaging systems are a potential non-invasive tool that could be used in the analysis of skin ulcers. With these systems it is possible to acquire optical images at different wavelengths which can then be processed by means of mathematical models based on optimization
\end{abstract}


approaches. The processing of those kind of images leads to the quantification of the main components of the skin. In the case of skin ulcers, these components could be correlated to the different stages of wound healing during the follow-up of a skin ulcer. This article presents the processing of a skin ulcer multi-spectral image. The ulcer corresponds to Leishmaniasis which is one of the diseases the most prominent in tropical areas. The image processing is performed by means of a light-tissue interaction model based on the distribution of the skin as a semi-infinite layer. The model, together with an optimization approach allows quantifying the main light-absorbing and scattering skin-parameters in the visible and near-infrared range. The results show significant differences between healthy and unhealthy area of the image.

Keywords: Multi-spectral images · Skin ulcers · Light-tissue model • Diffuse spectral reflectance.

\section{Introduction}

Skin ulcers (SU) are one of the most frequent causes of consultation in primary health-care units (PHU) in tropical areas. However, a large proportion of this pathology is misinterpreted due to the lack of specialized physicians. This fact leads to a prolonged time without a proper management to adopt the correct diagnosis and adequate therapy.

The development of non-invasive tools aims to improve the diagnosis and treatment of skin wounds. However, there are little efforts to find early diagnosis techniques in cases such as skin ulcers caused by Leishmaniasis. Thus, there is a need to investigate the potential use of novel non-invasive tools for the analysis of skin ulcer produced by tropical illnesses.

A technique of non-invasive analysis of human tissue that has been growing since the last decade is based on multi-spectral imaging systems. Those techniques allow quantifying the main components of human skin such as hemoglobin, melanin, beta-carotene, among others. Those kind of systems have been widely studied for the analysis of skin pathologies such as melasma, vitiligo, and even cancer $[1,2]$. Other kinds of human tissues that have been analyzed by these systems are: gastric [3] and cardiovascular [4] ones.

Multi-spectral images stand for the acquisition of images through a monochromatic camera once a tissue, or object of interest, is illuminated by different wavelengths. The set of acquired images represents at each pixel the diffuse reflectance of the tissue at the corresponding wavelength, assuming a pre-processing stage based on calibration or learning step. The obtained diffuse reflectance can be modeled by mathematical models that represents the light interaction with each one of the components that underlay the tissue $[5,6]$. By an inverse model procedure, based on an optimization approach, it is possible to obtain values that can be correlated to the quantification of the main components of the tissue under study [2]. In the case of skin, those values can be correlated to hemoglobin, melanin, collagen, among others. 
This article presents the application of a non-invasive multi-spectral imaging system oriented to the analysis of a Leishmaniasis skin ulcer. The analysis is based on the quantification of the skin components responsible of the phenomena of absorption and scattering of light in the visible and near infrared spectrum. The main goal will be to establish the relation of those parameters with the development of ulcers. The article is distributed as follows: Sect. 2 describes the system used for the acquisition of the multi-spectral skin ulcer images; also, the used light-tissue interaction model is presented in the same section. Section 3 presents the results obtained in a Leishmaniasis skin ulcer.

\section{Materials and Methods}

\subsection{ASCLEPIOS: A Multi-spectral Imaging System}

Skin ulcer multi-spectral image was obtained by means of a system named ASCLEPIOS which is based on interference optical filters [7,8]. The image acquisition set-up is composed of the following elements: a halogen white light source, a series of interference filters in the visible and near infrared region, a liquid wave guide, and an objective together with a CCD camera. The filters have a FWHM (Full Width at Half Maximum) of $80 \mathrm{~nm}$, and the central wavelength are between the range of $420 \mathrm{~nm}$ to $840 \mathrm{~nm}$. The interference filters allow illuminating the skin in the mentioned wavelengths. At each wavelength, a monochromatic image is acquired. At the end, a set of 10 images is obtained which is then processed by means of a neural-network based algorithm in order to obtain a set of 32 images. Those images compose a hyper-spectral image (HSI) which is in the range between $430 \mathrm{~nm}$ and $780 \mathrm{~nm}$ with a resolution of $10 \mathrm{~nm}$. At each pixel of the HSI, one spectrum is obtained. This spectrum is related with the values of the diffuse reflectance obtained when each wavelength interacts with the illuminated tissue. A description of the model used to analyze those obtained diffuse reflectances is explained in the following sub-section.

\section{$2.2 \quad$ Ligth-Tissue Interaction Model}

In a simple way, diffuse reflectance $R$ of skin can be modeled as a semi-infinite layer composed of elements that produce both light absorption and scattering. According to Zonios et al. [9], the diffuse reflectance can be expressed as described by the Eq. 1

$$
R=\frac{1}{1+\frac{\mu_{a}}{\mu_{s}}} ;
$$

where $\mu_{a}$ is the absorption component and $\mu_{S}$ the reduced scattering one. The latter is defined using the Mie theory [10], as a function of the refractive index $n$, diameter $d$ and volume fraction $V s$ of collagen particles. The former component can be described by Eqs. 2 through 5 as follows [11]:

$$
\mu_{a}=\mu_{a e p i}+\mu_{a d e r} ;
$$


with $\mu_{\text {aepi }}$ the absorption component at the epidermis, and $\mu_{\text {ader }}$ the absorption component at the dermis.

$$
\mu_{a e p i}=\mu_{a m e l}(\lambda) f_{m e l}+\mu_{a b a c k}(\lambda)\left(1-f_{m e l}\right) ;
$$

with $\mu_{a m e l}(\lambda)$ the theoretical absorption spectrum of melanin, $f_{m e l}$ the volume fraction of melanosomes, and $\mu_{a b a c k}(\lambda)$ the background absorption as presented by Eq. 4:

$$
\mu_{\text {aback }}(\lambda)=7.84 \times 10^{8} \lambda^{-3.255} ;
$$

$\mu_{\text {ader }}$ is the the absorption component at the dermis defined by Eq. 5 :

$$
\mu_{\text {ader }}=\mu_{\text {ablood }}(\lambda) f_{\text {blood }}+\mu_{\text {aback }}(\lambda)\left(1-f_{\text {blood }}\right) ;
$$

where $f_{\text {blood }}$ is the volume fraction of blood, and $\mu_{\text {ablood }}(\lambda)$ is the blood absorption due to oxyhemoglobin and deoxyhemoglobin.

This model can be used together with an optimization approach in order to quantify the concentration value of each component in a given HSI. This procedure is known as an inverse model.

The optimization approach applied to solve the inverse model is based on genetic algorithm. The aim of this algorithm is to find the values of the parameters that allow minimizing a cost function. In our case, this function corresponds to the mean squared error between the measured reflectance (the one obtained at each pixel) and the one obtained by the Eq. 1 when introducing values for the parameters $f_{\text {blood }}, f_{m e l}$, and collagen particles' diameter $d$. The values of these parameters are obtained during the development of the genetic algorithm. The principal steps of the implemented genetic algorithm are [12]:

1. Generation of the population of individuals: in this work, we use a population with a size of 20 individuals in the range defined for each parameter to be evaluated $\left(f_{\text {blood }}, f_{\text {mel }}\right.$, and $\left.d\right)$. The range of the parameters are defined by the literature [5]. The values are represented in a binary way.

2. Evaluation of the cost function: for each individual at the current population, the cost function is evaluated.

3. Reproduction: it is based on the roulette wheel selection method. This method allows obtaining a new group of 20 individuals, which are representative of the better cost values. This group constitutes the reproduction population.

4. Crossover: the binary values of the reproduction population are exchanged among them. This process leads to the crossover population.

5. Mutation: in this step, one bit from each individual at the crossover population is randomly chosen and changed from 0 to 1 or vice versa. This step generates the mutation population.

6. With the mutation population, steps 2 to 6 are repeated until achieving a minimum value for the cost functions. The final values of the parameters $f_{\text {blood }}, f_{\text {mel }}$, and $d$ are those that correspond to the lowest values of the obtained cost functions. 


\section{Results}

Light-skin model together with an optimization approach are used in order to analyze a HSI of one type of skin ulcer. The analyzed skin ulcer was caused by Leishmaniasis, which is a tropical disease present in many countries in Latin America. The results are shown in Figs. 1, 2 and 3.

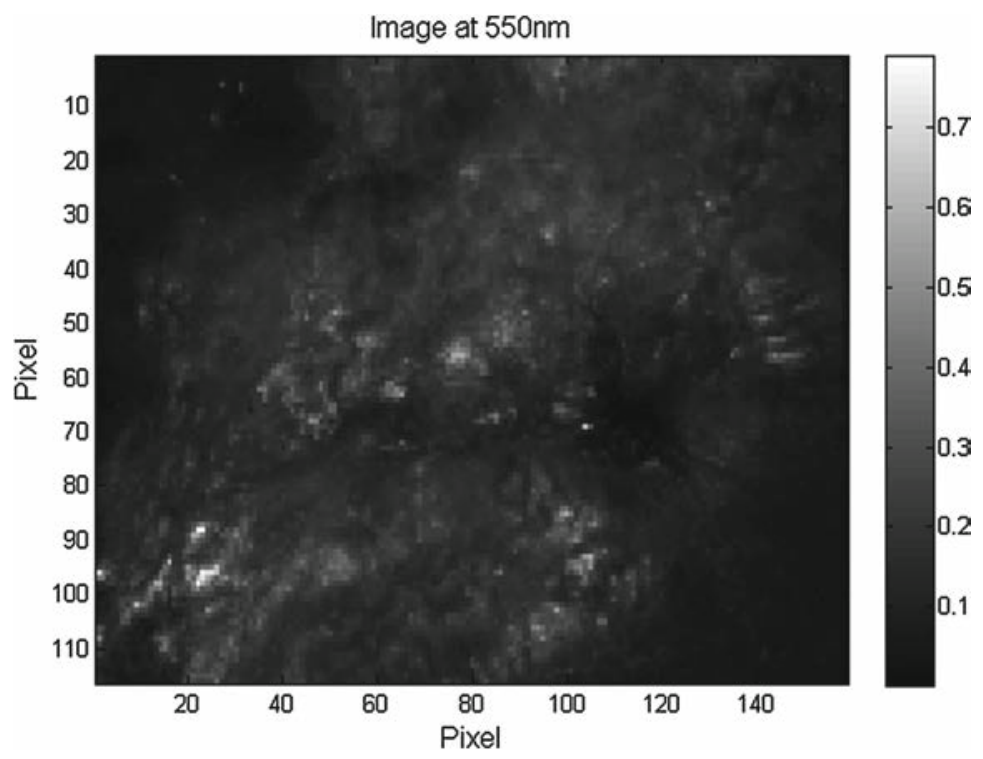

Fig. 1. Skin ulcer image at $550 \mathrm{~nm}$. Pixel values are the spectral reflectance.

Figure 1 presents the HSI acquired at the wavelength $550 \mathrm{~nm}$. In that image, it is possible to observe regions with healthy and non-healthy areas. Figures 2 and 3 show the results of the quantification of the hemoglobin and collagen component respectively. The result presented in Fig. 3 is representative of the light-scattering phenomena in the skin. It is possible to observe a correlation between the changes in spectral reflectance at $550 \mathrm{~nm}$ and the volume fraction of blood presented in Fig. 2.

The results in volume fraction of blood and collagen show differences between the healthy and unhealthy area. This difference could be representative for the analysis of the inflammatory and angiogenesis phases of skin-wound healing [13].

Although the image at $550 \mathrm{~nm}$ provides a pseudo-reference for the reader to discriminate between healthy and unhealthy tissues, the significance in multispectral images is the capacities of the technique to get concentration maps that can be correlated with the principal chromophores that compose skin tissue. Further studies, including histopathological tests, should be carried out. 


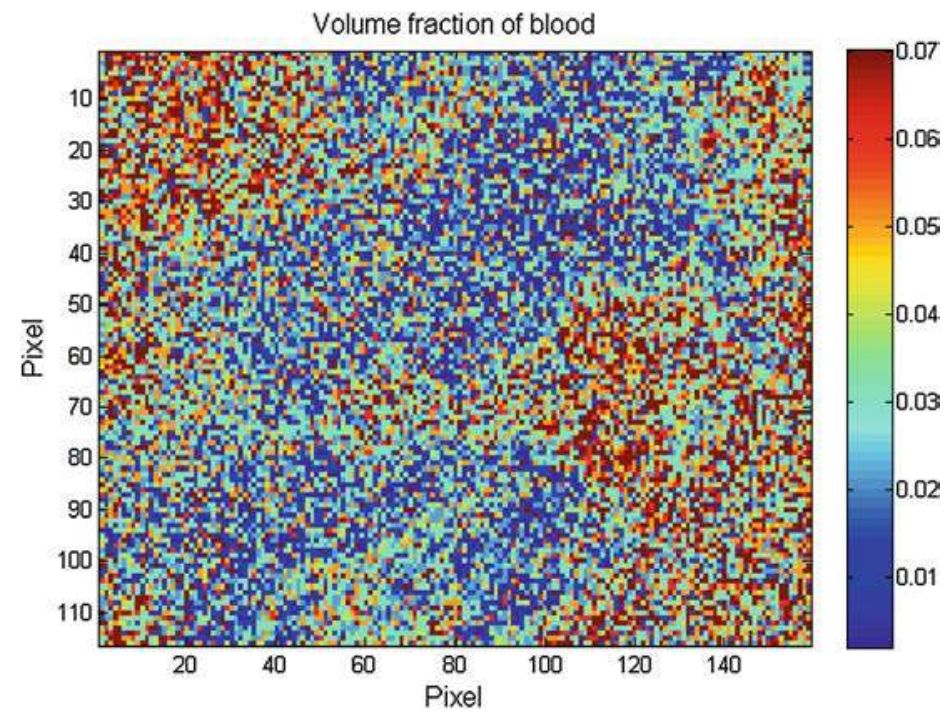

Fig. 2. Determination of the volume fraction of blood. Pixel values are given in normalized \%.

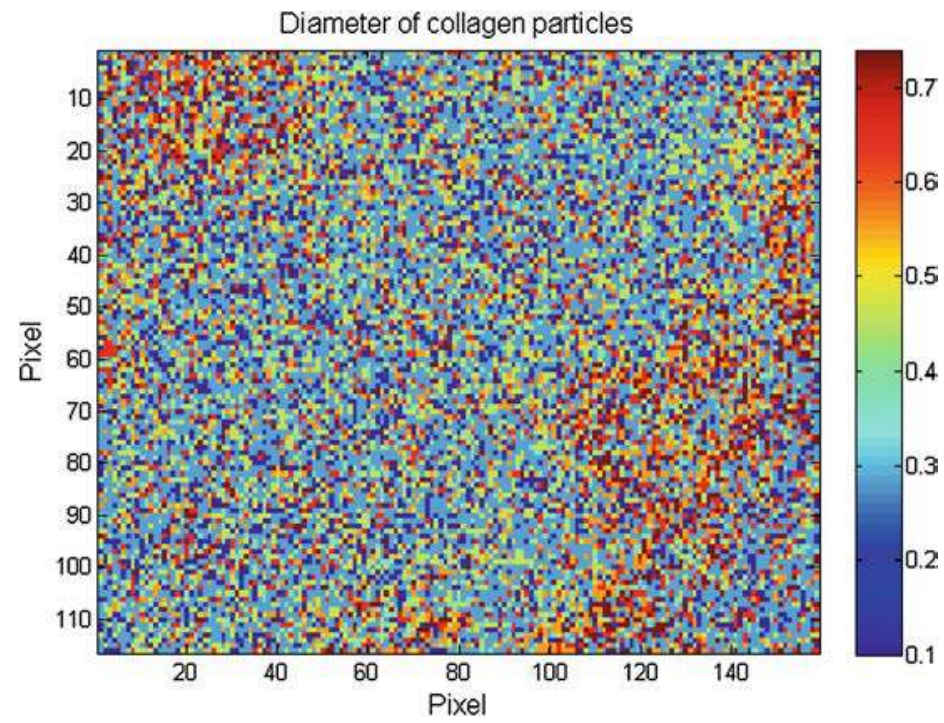

Fig. 3. Diameter of collagen. 


\section{Conclusions}

A semi-infinite layer-based model has been used in the study of a human skin ulcer Hyper Spectral Image. The image was obtained by a multi-spectral imaging system named ASCLEPIOS. The use of this model together with an optimization algorithm show that these approaches are a potential tool for the analysis of the principal components present in the skin: hemoglobin and collagen. The quantification of those components can be considered as indicators of the current state of a skin ulcer. For the specialists in dermatology, this can be used as indicator for the analysis and decisions to be held in order to apply a correct treatment to the patient. Nevertheless, the presented work needs further analysis for the study of the other major components underlying melanin and hemoglobin pigments. This work is a proof of concept of the use of multi-spectral images in the analysis of skin ulcers. Further works concern the use of a skin-light model that includes the parameter of skin thickness. Also, further experiments have to be carried out in order to obtain results with different skin ulcer phases, and comparisons with histopathological data.

Acknowledgements. The authors would like to acknowledge the medical support given by Dr. Brunella Raymundo Villalva and Dr. Francisco Bravo Puccio from Hospital Cayetano Heredia Lima-Perú. Also we acknowledge the support given by Dr. Benjamín Catañeda from Pontificia Universidad Católica del Perú and Dr. Jorge Arevalo from Universidad Peruana Cayetano Heredia. The authors also acknowledge the financial support given by the SticAmSud program (COLCIENCIA-INRIA-CONCYTEC) for the creation of the academical network IMPULSO (IMage Processing of skin ULcerS in trOpical areas).

\section{References}

1. Galeano, J., Jolivot, R., Marzani, F., Benezeth, Y.: Unmixing of human skin optical reflectance maps by Non-negative Matrix Factorization algorithm. Biomed. Sig. Process. Control 82, 169-175 (2013)

2. Jolivot, R., Benezeth, Y., Marzani, F.: Skin parameter map retrieval from a dedicated multispectral imaging system applied to dermatology/cosmetology. Int. J. Biomed. Imaging 26, 1-16 (2013)

3. Galeano, J., Jolivot, R., Benezeth, Y., Marzani, F., Emile, J.-F., Lamarque, D.: Analysis of multispectral images of excised colon tissue samples based on genetic algorithms. In: 2012 Eighth International Conference on Signal Image Technology and Internet Based Systems (SITIS), pp. 833-838. IEEE (2012)

4. Galeano, J., Perez, S., Montoya, Y., Botina, D., Garzón, J.: Blind source separation of ex-vivo aorta tissue multispectral images. Biomed. Opt. Express 65, 1589-1598 (2015)

5. Jacques, S.L.: Optical properties of biological tissues: a review. Phys. Med. Biol. 5811, R37 (2013)

6. Tuchin, V.V.: Tissue optics: light scattering methods and instruments for medical diagnosis. In: SPIE-International Society for Optical Engineering (2007) 
7. Jolivot, R., Vabres, P., Marzani, F.: Reconstruction of hyperspectral cutaneous data from an artificial neural network-based multispectral imaging system. Comput. Med. Imaging Graph. 352, 8588 (2011)

8. Mansouri, A., Marzani, F., Gouton, P.: Neural networks in two cascade algorithms for spectral reflectance reconstruction. In: ICIP, p. 718721 (2005)

9. Zonios, G., Aikaterini, D.: Modeling diffuse reflectance from semi-infinite turbid media: application to the study of skin optical properties. Opt. Express 1419, 8661-8674 (2006)

10. Mätzler, C.: MATLAB functions for Mie scattering and absorption, version 2. IAP Res. Rep. 8, 1-24 (2002)

11. Yudovsky, D., Laurent, P.: Rapid and accurate estimation of blood saturation, melanin content, and epidermis thickness from spectral diffuse reflectance. Appl. Opt. 4910, 1707-1719 (2010)

12. Rao, S.S., Rao, S.S.: Engineering Optimization: Theory and Practice. Wiley, Hoboken (2009)

13. UdDin, S., Greaves, N.S., Anil, S., Baguneid, M., Bayat, B.: Noninvasive device readouts validated by immunohistochemical analysis enable objective quantitative assessment of acute wound healing in human skin. Wound Repair Regen. 236, 901-914 (2015) 